\title{
Sample preference for colorectal cancer screening tests: Blood or stool?
}

\author{
Joanne M. Osborne ${ }^{1,2^{*}}$, Carlene Wilson ${ }^{1}$, Vivienne Moore ${ }^{3}$, Tess Gregory ${ }^{1}$, Ingrid Flight ${ }^{4}$, \\ Graeme P. Young ${ }^{1}$
}

${ }^{1}$ Flinders Centre for Cancer Prevention and Control, Flinders University of South Australia, Adelaide, Australia;

*Corresponding Author: jo.osborne@health.sa.gov.au

${ }^{2}$ Bowel Health Service, Repatriation General Hospital, Adelaide, Australia

${ }^{3}$ Discipline of Public Health, University of Adelaide, Adelaide, Australia

${ }^{4}$ CSIRO Preventative Research Flagship, Adelaide, Australia

Received 17 April 2012; revised 20 May 2012; accepted 12 June 2012

\section{ABSTRACT}

Objective: Despite the high prevalence of CRC and the proven benefits of faecal sampling tests, participation rates in CRC screening are suboptimal. Literature has identified a number of barriers to participation, including faecal aversion. Emerging test technologies suggest blood-based molecular markers might provide an alternative, more acceptable option, for CRC screening tests. We aim to determine preference for blood compared to faeces as the sample for the screening test. Methods: A survey was mailed to 956 South Australians aged 50 to $\mathbf{7 4}$ years. Data were collected on sample preference, demographic variables, and ratings of screening test convenience and comfort. Results: The survey yielded a $43 \%$ response rate. The majority of participants preferred to provide a blood sample $(78 \%$ vs $22 \%$, $p$ $<0.001)$. Women were more likely to prefer blood than men $(82 \%$ vs $74 \%, p=0.05)$. Sample experience influenced preferences, with a significantly higher preference for faeces among participants with experience in faecal sampling ( $27 \%$ vs $17 \%$ with no experience, $p<0.05$ ). Participants who preferred to provide a faecal sample rated it significantly more convenient $(p<$ $0.001)$, more comfortable ( $p<0.001$ ), and more acceptable $(p<0.001)$ than those who preferred blood sampling. Conclusions: Survey participants overwhelmingly indicate a preference for the idea of a blood sample over a faecal sample for CRC screening. Preference was influenced by gender, experience with sampling method and the individual's perception of sampling convenience, sampling comfort and sample acceptability. Our results suggest population participation rates are likely to improve with blood- based screening tests.

Keywords: Colon Cancer Screening; Faecal Occult Blood Test; Sample Preference; Stool Sampling; Blood Sampling; Participation

\section{INTRODUCTION}

Colorectal cancer (CRC) is the second most prevalent cancer in Australia [1], similar to the situation in many other developed countries. Despite the high prevalence of $\mathrm{CRC}$ in Australia, and proven benefits of screening using Faecal Occult Blood Tests (FOBT) [2-5], participation rates in faecal-based CRC screening are suboptimal (40.1\%) [6].

Achieving a high participation rate is crucial as early (curable) lesions will only be detected in individuals who participate in screening [7]. Therefore, the target population must find the screening test acceptable and be willing to undertake the offered test. Research examining attitudes toward FOBT has identified a number of participation barriers, including faecal aversion [8].

There is limited evidence available on patient preference for sample provision $[9,10]$, and it is consequently difficult to judge how blood sampling would be viewed even though there is a general perception that it would be preferred to an FOBT. Although a large percentage of the population believe that blood sampling is a good source of information relevant to diagnosis and decision-making about health [11], a recent study suggests the existence of significant levels of "blood-injury-injection" phobia among both healthy $(19.5 \%)$ and patient $(30.1 \%)$ participants [12].

The relative acceptability of blood sampling for CRC screening compared to FOBT remains to be established. Moreover, in order to optimise participation rates in CRC screening it is important to establish the extent to which 
any preference varies according to demographic variables and past sampling experience. The aims of our study were to: 1) Determine whether people prefer to provide a blood sample or a faecal sample for a CRC screening test; and 2) Investigate whether age, gender, residential location, marital status, employment status, education and familiarity with sampling, influence sample preference for a CRC screening test.

\section{METHODS}

\subsection{Study Population}

The Australian Electoral Commission provided a random selection of names and addresses of males or females, aged 50 to 74 years residing in the South Australian metropolitan electorates of Adelaide, Port Adelaide and Sturt and the South Australian rural electorate of Barker. This range of urban and rural areas of varying socio-economic distributions was targeted to investigate whether these factors influenced sample preference.

\subsection{Survey Administration}

Survey questions were devised to capture information on the extent to which preference for sampling technolo- gies varied according to demographic variables; and to measure participant familiarity with blood and faecal testing. Participants' perceptions of both sampling procedures in terms of comfort, convenience and overall perceived acceptability was rated using a 7-point Likert scale ranging from $1=$ Highly Inconvenient/Uncomfortable/Unacceptable, to $7=$ Highly Convenient/Comfortable/Acceptable respectively. All participants were asked to nominate either blood or stool (faeces) sampling as their preferred CRC screening approach.

\subsection{Survey Distribution}

Data were collected via a mail-distributed paper survey. An advance notification letter was sent two weeks pre-survey distribution. The survey was posted with an invitation letter, complaints procedure form, and a replypaid envelope. Three weeks post-survey distribution, a reminder package was posted containing a reminder letter, replacement survey and a reply-paid envelope. Consent to participate was implied by return of a completed survey (see Figure 1).

\subsection{Statistical Analyses}

We identified factors associated with preference using

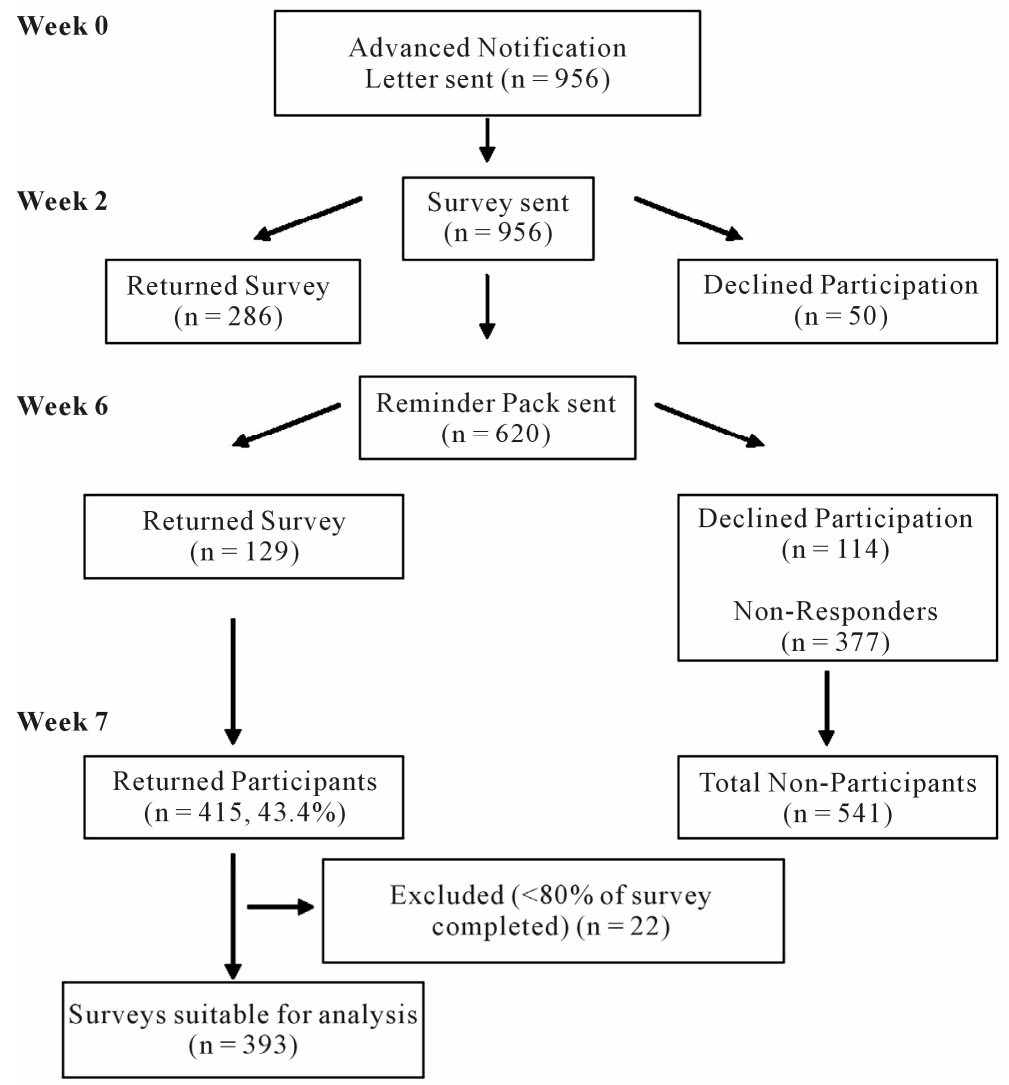

Figure 1. Survey administration and response flow diagram. 
Chi-squared analyses, non-parametric tests (e.g. Mann Whitney U Test) and independent samples t-tests according to the nature of the data. Where tests yielded results with the same levels of significance, Independent samples t-test data is shown. All data analyses were undertaken using Statistical Package for the Social Sciences (SPSS) Version 18 or an online statistical calculator [13]. Participants who completed $<80 \%$ of survey questions were excluded from all analyses. Participants who missed individual questions were excluded case-wise from specific analyses.

\subsection{Ethical Approval}

Ethics approval was obtained from the Flinders Clinical Research Ethics Committee, Flinders Medical Centre and The University of Adelaide Human Research Ethics Committee. Invitees were assigned a unique study identification number. Survey responses were only identified by this number.

\section{RESULTS}

\subsection{Response Rate and Participant Demographics}

The survey yielded a 43.4\% (415/956) response rate (see Figure 1). Twenty two participants were excluded from analysis due to insufficient responses. Demographic groups were well represented with participation evenly distributed across invited groups. There were no significant differences in age, gender, residential location or Socio-Economic Indexes for Areas (SEIFA) between responders and non-responders, data not shown.

\subsection{Sample Preference According to Demographic Characteristics}

The majority of participants preferred to provide a blood sample (78\% vs $\left.22 \%, \chi^{2}(1)=123.3, \mathrm{p}<0.001\right)$. Preference for a blood sample over a faecal sample was consistent across all demographic groups, however, within subgroups, differences in sample preference were observed (see Table 1). A higher proportion of females preferred to provide a blood sample compared to males $\left(82 \%\right.$ vs $\left.74 \%, \chi^{2}(1)=3.69, \mathrm{p}=0.05\right)$. Sample preference did not differ significantly between residential locations $\left(\chi^{2}(1)=0.13, \mathrm{p}>0.05\right)$, however, a significantly higher proportion of metropolitan males preferred faecal sampling compared to metropolitan females, (27\% vs $16 \%$, $\left.\chi^{2}(1)=5.68, \mathrm{p}<0.05\right)$.

Marital Status and Education level significantly influenced preference with married/defacto people significantly more likely to prefer a faecal sample compared to widowed, single or divorced people $\left(24 \%\right.$ vs $11 \%, \chi^{2}(1)$ $=6.27, \mathrm{p}<0.05)$; and people who had at least completed
Table 1. Preference according to demographic characteristics.

\begin{tabular}{|c|c|c|c|c|}
\hline $\begin{array}{l}\text { Demographic } \\
\text { Characteristics }\end{array}$ & $\mathrm{n}=$ & $\begin{array}{l}\text { Blood } \\
\text { Preference } \\
\text { Group }\end{array}$ & $\begin{array}{l}\text { Faeces } \\
\text { Preference } \\
\text { Group }\end{array}$ & $\begin{array}{c}\text { Pearson }\left(\chi^{2}\right) \\
\quad(p \text { value })\end{array}$ \\
\hline \multicolumn{5}{|l|}{ Gender } \\
\hline Male & 193 & 143 & 50 & $p=0.05$ \\
\hline Female & 196 & 161 & 35 & \\
\hline \multicolumn{5}{|l|}{ Residential Location } \\
\hline Metropolitan & 285 & 224 & 61 & $\mathrm{p}>0.05$ \\
\hline Rural & 104 & 80 & 24 & \\
\hline \multicolumn{5}{|l|}{ Age (years) } \\
\hline $50-54$ & 68 & 54 & 14 & \multirow{5}{*}{$\mathrm{p}>0.05$} \\
\hline $55-59$ & 88 & 70 & 18 & \\
\hline $60-64$ & 79 & 57 & 22 & \\
\hline $65-69$ & 82 & 66 & 16 & \\
\hline $70-74$ & 72 & 57 & 15 & \\
\hline \multicolumn{5}{|l|}{ Marital Status } \\
\hline Married/Defacto & 302 & 229 & 73 & \multirow[t]{2}{*}{$\mathbf{p}<0.05$} \\
\hline $\begin{array}{l}\text { Widowed/Single/ } \\
\text { Divorced }\end{array}$ & 80 & 71 & 9 & \\
\hline \multicolumn{5}{|l|}{ Employment Status } \\
\hline $\begin{array}{c}\text { Employed Full Time } \\
\text { or Part Time }\end{array}$ & 181 & 139 & 42 & \multirow[t]{2}{*}{$\mathrm{p}>0.05$} \\
\hline $\begin{array}{c}\text { Unemployed, Retired, } \\
\text { Home Duties }\end{array}$ & 201 & 183 & 40 & \\
\hline \multicolumn{5}{|l|}{ Education Level } \\
\hline $\begin{array}{c}\text { Did Not Complete } \\
\text { Yr } 12\end{array}$ & 131 & 111 & 20 & \multirow[t]{2}{*}{$\mathbf{p}<0.05$} \\
\hline $\begin{array}{c}\text { Completed Yr } \\
\text { 12/Completed Tertiary } \\
\text { Education }\end{array}$ & 244 & 183 & 61 & \\
\hline \multicolumn{5}{|l|}{ SEIFA $^{a}$} \\
\hline $1^{\text {st }}$ Quartile & 84 & 70 & 14 & \multirow{4}{*}{$\mathrm{p}>0.05$} \\
\hline $2^{\text {nd }}$ Quartile & 92 & 71 & 21 & \\
\hline $3^{\text {rd }}$ Quartile & 103 & 82 & 21 & \\
\hline $4^{\text {th }}$ Quartile & 110 & 81 & 29 & \\
\hline
\end{tabular}

${ }^{\mathrm{a}} \mathrm{SEIFA}=$ Socio-Economic Indexes for Areas.

Year 12, were significantly more likely to prefer a faecal sample, than those who did not complete Year $12(25 \%$ vs $\left.15.3 \%, \chi^{2}(1)=4.52, \mathrm{p}<0.05\right)$.

There was no significant difference in sample preference across age bands $\left(\chi^{2}(4)=2.134, \mathrm{p}>0.05\right)$, employment status $\left(\chi^{2}(1)=0.6167, \mathrm{p}>0.05\right)$, or SEIFA 
quartiles $\left(\chi^{2}(3)=2.81, \mathrm{p}>0.05\right)$, with all of these subgroups having a higher preference for a blood sample.

\subsection{Sample Preference According to Familiarity with Sampling Procedures}

Participants were more likely to have had experience providing a blood sample $(97.4 \%)$ than a faecal sample $(48 \%)$. There were no significant differences in faecal sample experience across any of the demographic groups (see Table 2).

As virtually everyone had experienced blood sampling, subsequent analyses explored sampling preference among participants based on their experience (yes or no) of faecal sampling. Sample experience influenced preferences, with a significantly higher preference for faeces among participants with faecal sampling experience $(26 \%$ vs $\left.18 \%, \chi^{2}(1)=4.0199, \mathrm{p}<0.05\right)$ (see Table 3).

\subsection{Sample Preference According to Convenience, Comfort and Overall Acceptability of Samples}

The Faeces Preference Group (FPG) rated the convenience, comfortable and overall acceptability of faecal sampling significantly higher than the Blood Preference Group (BPG) (see Table 4).

The convenience of blood sampling was rated significantly lower by the FPG compared to the BPG. The mean rating score for the comfort and overall acceptability of a blood sample did not differ significantly between preference groups (see Table 4).

\section{DISCUSSION}

Our results showed that people overwhelmingly preferred to provide a blood sample over a faecal sample for a CRC screening test.

Metropolitan males, married/defacto people, those who completed at least a Year 12 education and those with FOBT experience were the subgroups most likely to prefer a faecal sample, but overall, even these subgroups, still preferred the idea of a blood sample. Our results found other demographic variables (i.e. age, SEIFA and employment status) had no influence on sample preference.

Our findings show that the proportion of men who prefer faecal sampling is higher than the proportion of females, which seems at odds with the observations that women are more willing to participate in FOBT-based screening [14]. Our results indicate that moving to a blood sample may not necessarily improve participation rates across both genders to the same degree.

Social support, which has been shown to increase participation in FOBT screening [8], may explain why those
Table 2. Familiarity with FOBT according to demographic characteristics.

\begin{tabular}{|c|c|c|c|c|}
\hline \multirow{2}{*}{$\begin{array}{l}\text { Demographic } \\
\text { Characteristic }\end{array}$} & \multirow{2}{*}{$\begin{array}{c}\text { Total } \\
\mathrm{n}=\end{array}$} & \multicolumn{2}{|c|}{$\begin{array}{l}\text { Experience with } \\
\text { FOBT }\end{array}$} & \multirow{2}{*}{$\begin{array}{c}\text { Pearson }\left(\chi^{2}\right) \\
(\mathrm{p} \text { value })\end{array}$} \\
\hline & & YES & NO & \\
\hline \multicolumn{5}{|l|}{ Gender } \\
\hline Male & 195 & 98 & 97 & $\mathrm{p}>0.05$ \\
\hline Female & 195 & 100 & 95 & \\
\hline \multicolumn{5}{|l|}{ Residential Location } \\
\hline Metropolitan & 285 & 144 & 141 & $\mathrm{p}>0.05$ \\
\hline Rural & 105 & 54 & 51 & \\
\hline \multicolumn{5}{|l|}{ Age (years) } \\
\hline $50-59$ & 155 & 76 & 79 & $\mathrm{p}>0.05$ \\
\hline $60-74$ & 235 & 122 & 113 & \\
\hline \multicolumn{5}{|l|}{ Marital Status } \\
\hline Married/Defacto & 303 & 148 & 155 & $\mathrm{p}>0.05$ \\
\hline $\begin{array}{l}\text { Widowed/Single/ } \\
\text { Divorced }\end{array}$ & 80 & 46 & 34 & \\
\hline \multicolumn{5}{|l|}{ Employment Status } \\
\hline $\begin{array}{l}\text { Employed Full Time or } \\
\text { Part Time }\end{array}$ & 180 & 95 & 85 & $\mathrm{p}>0.05$ \\
\hline $\begin{array}{c}\text { Unemployed, Retired, } \\
\text { Home Duties }\end{array}$ & 203 & 99 & 104 & \\
\hline \multicolumn{5}{|l|}{ Education Level } \\
\hline $\begin{array}{l}\text { Did Not Complete } \\
\text { Yr } 12\end{array}$ & 132 & 72 & 60 & $\mathrm{p}>0.05$ \\
\hline $\begin{array}{c}\text { Completed Yr } \\
\text { 12/Completed Tertiary } \\
\text { Education }\end{array}$ & 247 & 121 & 126 & \\
\hline \multicolumn{5}{|l|}{ SEIFA $^{a}$} \\
\hline $1^{\text {st }}$ Quartile & 83 & 46 & 37 & \\
\hline $2^{\text {nd }}$ Quartile & 92 & 48 & 44 & $\mathrm{p}>0.05$ \\
\hline $3^{\text {rd }}$ Quartile & 103 & 54 & 49 & \\
\hline $4^{\text {th }}$ Quartile & 112 & 50 & 62 & \\
\hline
\end{tabular}

${ }^{\mathrm{a}} \mathrm{SEIFA}=$ Socio-Economic Indexes for Areas.

Table 3. Preference according to experience with FOBT.

\begin{tabular}{cccc}
\hline $\begin{array}{c}\text { Experience with } \\
\text { FOBT }\end{array}$ & $\mathrm{n}=$ & $\begin{array}{c}\text { Blood Preference } \\
\text { Group }\end{array}$ & $\begin{array}{c}\text { Faeces Preference } \\
\text { Group }\end{array}$ \\
\hline YES & 190 & $140(74 \%)$ & $50(26 \%)$ \\
NO & 196 & $161(82 \%)$ & $35(18 \%)$ \\
\hline
\end{tabular}


Table 4. Preference according to perception of sample acceptability.

\begin{tabular}{lcccc}
\hline \multicolumn{1}{c}{ Acceptability Rating } & $\begin{array}{c}\text { Blood Preference Group } \\
(\text { Mean } \pm \text { SD) }\end{array}$ & $\begin{array}{c}\text { Faeces Preference Group } \\
(\text { Mean } \pm \text { SD) }\end{array}$ & $\mathrm{t}$ & $\mathrm{p}$ value \\
\hline Faeces Convenience & $4.61 \pm 1.87$ & $6.45 \pm 1.05$ & 11.62 & 0.00 \\
Blood Convenience & $6.32 \pm 1.15$ & $5.88 \pm 1.58$ & -2.38 & 0.00 \\
Faeces Collection Comfort & $5.10 \pm 1.89$ & $6.72 \pm 0.65$ & 12.54 & 0.00 \\
Blood Collection Comfort & $6.59 \pm 0.93$ & $6.36 \pm 1.17$ & -1.61 & 0.11 \\
Overall Acceptability of Faeces & $5.23 \pm 1.80$ & $6.70 \pm 0.66$ & 11.72 & 0.00 \\
Overall Acceptability of Blood & $6.55 \pm 0.98$ & $6.42 \pm 1.10$ & -1.08 & 0.28 \\
\hline
\end{tabular}

who were married or in defacto relationships were more amenable to a faecal sample, but as we observed no differences in FOBT experience within the marital status variable, the higher preference for a faecal sample in this group is unexpected.

Education, which has been associated with increased awareness of FOBT screening [8], may account for our observation that those with a higher education were more amenable to a faecal sample as this type of sample is known to be the current screening test. Qualitative research unpublished by the authors, observed that people with a preference for a faecal sample chose this sample because it was derived from the intestine and therefore was thought to have higher efficacy than a blood sample.

These interesting findings highlight the importance of exploring the link between acceptability of samples and participation in screening. Once accurate blood-based tests are identified, randomised-controlled trials using participation rates as the outcome are needed to understand actual behaviour relative to intention.

Experience was evenly distributed amongst the subgroups with almost everyone in the subgroups having experience providing a blood sample, compared to about half having FOBT experience. Despite the strong preference for a blood sample overall, familiarity clearly influenced sample preference. Participants with faecal sampling experience were more amenable to a faecal sample than participants with no faecal sampling experience. This finding fits in with experience in many arenas which shows that familiarity can overcome perceived barriers. As people become more familiar with faecalbased screening, the observed difference in preference might not be as apparent.

Participant's perceptions of sampling convenience, comfort and acceptability influenced sample preference. The extent to which specific sampling attributes impacted on preference is difficult to assess accurately from the rating scale measures used; future research should address the relative importance of attributes using techniques such as conjoint analysis [15]. In this study, those who preferred a blood sample rated blood considerably more acceptable than a faecal sample, whereas those who preferred faecal sampling, and rated faeces as more acceptable than blood, also rated blood as a highly acceptable sample. This finding suggests that even those participants, who chose faeces as their preferred sample, would still find a blood sample highly acceptable for a CRC screening test.

Among those who preferred a faecal sample, faeces was rated as being more convenient than a blood sample. This finding implies that faecal sampling, which is usually performed at home and distributed through the postal system, may be considered more convenient than attending a clinic or doctor's appointment to provide a blood sample. Further evaluation of the perceived convenience of different aspects of the sampling procedures, and their importance to the decision-making process, would be required before this assumption can be confirmed.

Less than half of invitees responded, and caution is needed in generalising these findings, however, it is a strength of the study that the views of respondents across genders, metropolitan and rural areas as well as SEIFA were well represented, with proportional participation rates across groups, therefore the sample was representative of the population of Australia. However, the ages of those who participated in the survey differ significantly from the Australian population, with people aged over 60 more likely to participate than people aged under 60 , indicating caution when generalising these findings to the general population.

Our findings indicate that a blood test for colorectal cancer may be more acceptable to the public than a faecal test as this research shows a preference for the idea of a blood test. This suggests that participation rates in population screening could be improved by a change to the sampling approach. Caution is required with study interpretation as we need to determine if their perceived preference translates into real differences in uptake in practice. Validation of blood markers for CRC screening is ongoing and it is important that this work consider data on screening protocol acceptability. Variables likely 
to affect uptake, over and above sample type, include perceived test efficacy, cost and testing frequency and future research should examine these. If a blood-based test is implemented in practice, consideration of how different subgroups view a faecal or blood sample needs deliberation. For maximum participation in CRC screening, perhaps both a blood and a faecal test should be offered to target preference differences between subgroups.

\section{REFERENCES}

[1] Australian Institute of Health and Welfare (2008) Australia's health 2008. AIHW, Canberra.

[2] Mandel, J.S., Bond, J.H., Church, T.R., et al. (1993) Reducing mortality from colorectal cancer by screening for fecal occult blood. New England Journal of Medicine, 328, 1365-1371. doi:10.1056/NEJM199305133281901

[3] Hardcastle, J.D., Chamberlain, J.O., Robinson, M.H., et al. (1996) Randomised controlled trial of faecal-occultblood screening for colorectal cancer. Lancet, 348, 14721477. doi:10.1016/S0140-6736(96)03386-7

[4] Kronborg, O., Fenger, C., Olsen, J., et al. (1996) Randomised study of screening for colorectal cancer with faecal-occult-blood test. Lancet, 348, 1467-1471. doi:10.1016/S0140-6736(96)03430-7

[5] Lindholm, E., Brevinge, H. and Haglind, E. (2008) Survival benefit in a randomized clinical trial of faecal occult blood screening for colorectal cancer. British Journal of Surgery, 95, 1029-1036. doi:10.1002/bjs.6136

[6] Australian Institute of Health and Welfare (2010) National bowel cancer screening program: Annual monitoring report 2009 data supplement 2010. Cancer series no 57 cat no CAN53. AIHW, Canberra.

[7] Australian Cancer Network Cancer Guidelines Revision Committee (2005) Guidelines for the prevention, early detection and management of colorectal cancer. The
Cancer Council Australia and Australian Cancer Network, Sydney.

[8] Weitzman, E.R., Zapka, J., Estabrook, B. and Goins, K.V. (2001) Risk and reluctance: Understanding impediments to colorectal cancer screening. Preventive Medicine, 32, 502-513. doi:10.1006/pmed.2001.0838

[9] Koka, S., Beebe, T.J., Merry, S.P., et al. (2008) The preferences of adult outpatients in medical or dental care settings for giving saliva, urine or blood for clinical testing. Journal of the American Dental Association, 139, 735740.

[10] Nayaradou, M., Berchi, C., Dejardin, O. and Launoy, G. (2010) Eliciting population preferences for mass colorectal cancer screening organization. Medical Decision Making, 30, 224-233. doi:10.1177/0272989X09342747

[11] Pfeffer, N. and Laws, S. (2006) "It's only a blood test": What people know and think about venepuncture and blood. Social Science \& Medicine, 62, 3011-3023. doi:10.1016/j.socscimed.2005.11.050

[12] Kose, S. and Mandiracioglu, A. (2007) Fear of blood/injection in healthy and unhealthy adults admitted to a teaching hospital. International Journal of Clinical Practice, 61, 453- 457. doi:10.1111/j.1742-1241.2006.01150.x

[13] Chinese University of Hong Kong, Dept OBG (2010). http://department.obg.cuhk.edu.hk/researchsupport/RxC contingency table.ASP,2010

[14] Javanparast, S., Ward, P. and Cole, S. (2010) A crosssectional analysis of participation in National Bowel Cancer Screening program in Adelaide by age, gender and geographical location of residence. Australasian Medical Journal, 1, 141-146. doi:10.4066/AMJ.2010.198

[15] Phillips, K., Johnson, F. and Maddala, T. (2002) Measuring what people value: A comparison of "attitude" and "preference" surveys. Health Services Research, 37, 16591679. doi:10.1111/1475-6773.01116 